\title{
XLIX. On the different systems of measures for electric and magnetic quantities
}

\section{Prof. R. Clausius}

To cite this article: Prof. R. Clausius (1882) XLIX. On the different systems of measures for electric and magnetic quantities, Philosophical Magazine Series 5, 13:83, 381-398, DOI: $10.1080 / 14786448208627203$

To link to this article: http://dx.doi.org/10.1080/14786448208627203

册 Published online: 28 Apr 2009.

Submit your article to this journal $[\pi$

Џ Article views: 6

Q View related articles $\asymp$ 
LONDON, EDINBURGH, AND DUBLIN

\title{
PHILOSOPHICAL MAGAZINE
}

\author{
AND \\ JOURNAL OF SCIENCE. \\ [FIFTH SERIES.] \\ $J U N E 1882$.
}

XLIX. On the different Systems of Measures for Electric and Magnetic Quantities. By Prof. R. Clausius*.

GOR the measurement of electric and magnetic quantities, it is well known that two essentially different systems, usually called the electrostatic and the electromagnetic, are employed. Both reduce the determination of electric and magnetic quantities to the measurement of mass, length, and time; but in the manner of the reduction they differ from each other more considerably than is usually the case with other different systems of measures. While in the ordinary mechanical quantities (such as velocities, forces, and mechanical work) the different measuring-systems employed are distinguished from one another only by the so-called fundamental units, viz. the units of mass, length, and time, having different values, in the two above-mentioned systems applied to electricity and magnetism the formulce which serve for the determination of one and the same quantity are also different, since they contain different powers of the fundamental units.

The deduction of these formulæ is systematically carried out with singular completeness in Clerk Maxwell's splendid work, 'A Treatise on Electricity and Magnetism,' Oxford, 1873; and the high estimation in which Maxwell is justly held could not fail to cause his formulæ not only to be accepted in

* Translated from a separate impression, communicated by the Author, from the Verhandl. des naturhist. Vereins der preuss. Rheinlande und Westfalens, vol. xxxix. (1882). Read at the meeting of the Niederrheinische Gesellschaft für Natur- und Heilkunde, on the 6th March, 1882.

Phil. Mag. S. 5. Vol. 13. No. 83. June 1882. $2 \mathrm{G}$ 
England as correct throughout, but also to be adopted unaltered in the works of writers belonging to other nations. In regard to the latter, I will mention only Mascart and Joubert's valuable Leçons sur l'Electricité et le Magnétisme (Paris, 1882), and Herwig's useful book, Physikalische Begriffe und absolute Maasse (Leipzig, 1880).

Nevertheless I think I can show that Maxwell has committed an error in his development, by which several of his formulæ have been rendered incorrect. The correction of this mistake appears to me to be especially necessary just now, since at the present time the attention of wider circles than formerly is directed to this subject by the decisions of the Congress of Electricians at Paris upon the electrical units of measurement, and hence an error remaining uncorrected might be mischievously disseminated and fixed. It also appears to me that Maxwell's exposition of the subject (which is not all collected together in one passage of his book, but appears in portions in different parts of it) presents some difficulty to the understanding. Hence I think that a connected presentation of the thing, as simple and distinct as possible, will not be unwelcome.

\section{§1. The Fundamental Units and the first General Equation of each System.}

As already mentioned above, the units of mass, length, and time are employed as fundamental units. After Maxwell, it is usual to denote them by enclosing in square brackets the letters which are generally employed to represent those three kinds of quantity. Thus the unit of mass is [M], the unit of length $[\mathrm{L}]$, and the unit of time $[\mathrm{T}]$.

From these are immediately obtained the units of various other quantities. That velocity with which a unit of length is passed through in the unit of time is employed as the unit of velocity; hence, for its representation, we have to divide the unit of length by the unit of time, and we get the formula $\left[\mathrm{LT}^{-1}\right]$. The unit of force is that force which imparts the unit of velocity to the unit of mass in the unit of time; hence we obtain the formula which serves to represent it, if we divide the product of the mass-unit and the velocity-unit by the timeunit, whence arises $\left[\mathrm{MLT}^{-2}\right]$. The unit of mechanical work is that work which is done by the force-unit along a path equal to the length-unit; and therefore, in order to represent it, we need only to multiply the force-unit by the length-unit, by which we get $\left[\mathrm{ML}^{2 \mathrm{~T}^{-2}}\right]$.

Now, for the measurement of electricity we must employ 
the forces exerted by it. These are of two essentially different kinds:-first, the forces independent of its motion, which amounts of electricity always exert upon one another whether they are at rest or in motion; secondly, the forces arising only through the motion. The former are named the electrostatic, and the latter the electrodynamic forces. To the electrodynamic we must reckon the magnetic forces, if we with Ampère derive the explanation of magnetism from small electric currents taking place in the interior of the magnet. Now, of these two forces, we can apply either the one or the other to the measurement of electricity; and thence arise those two systems of measures, of which the former is called the electrostatic, while the latter (as already said) is ordinarily named the electromagnetic, but would be more rationally called the electrodynamic. In those cases in which it is self-evident that electrical systems of measures are meant, one can, for convenience, omit the prefix "electro," and, briefly, speak of static and dynamic measuring-systems.

In the electrostatic system the most important unit, which serves as the basis of all the others, is the unit of electricity. This is determined by the following definition:-The unit of electricity is that amount of electricity which exerts the unit of force upon an equal amount of electricity at the unit of distance. We can therefore put the unit of force equal to a fraction having the square of the electricity-unit for its numerator and the square of the length-unit for its denominator. We will at the same time denote, with Maxwell, the electricity-unit by enclosing the letter $e$ in square brackets; but, in order to express that the static electricity-unit is intended, we will provide the $e$ with the index $s$, so that the symbol will have the form $\left[e_{s}\right]$. The equation in question will then read:-

$$
\frac{\left[e_{s}^{2}\right]}{\left[\mathrm{L}^{2}\right]}=\left[\mathrm{MLT}^{-2}\right]
$$

and from this follows

$$
\left[e_{s}\right]=\left[\mathrm{M}^{\frac{1}{2}} \mathrm{~L}^{\frac{3}{2}} \mathrm{~T}^{-1}\right] . . . . . .
$$

In the electrodynamic system of measures, it would first suggest itself, from what has been said above, to take as the standard that force which, in addition to the static force, two moved quantities of electricity exert upon each other in consequence of their motion. Respecting this force, however, differences of opinion prevail, which make the choice of it as the starting-point of the determinations inexpedient. On the other hand, the forces exerted upon each other by closed electric currents can be regarded as indubitably known. As, $2 \mathrm{G} 2$ 
further, the little electric currents which, according to Ampère, must be assumed to flow in the interior of a magnet are likewise closed, we have in magnetism to do with forces of the same kind, and hence we can also select as the standard the force exerted upon one another by two quantities of magnetism. This latter is the most convenient, because magnetic forces can be more simply expressed than the forces exerted between larger closed currents. Accordingly, in the electrodynamic system the unit of magnetism is determined, in precise correspondence with the unit of electricity in the electrostatic system, by the following definition:-The unit of magnetism is that amount of magnetism which exerts upon an equal amount of magnetism at the unit of distance the unit of force.

For the mathematical representation, we, again with Maxwell, denote the unit of magnetism by a square-bracketed $m$; but, in order to indicate that the unit in question is the dynamic unit, we annex a $d$ as index, so that the symbol has the form $\left[m_{d}\right]$; and with this we form the equation

whence results

$$
\frac{\left[m_{d}^{2}\right]}{\left[\mathrm{L}^{2}\right]}=\left[\mathrm{MLT}^{-2}\right] \text {, }
$$

$$
\left[m_{d}\right]=\left[M^{\frac{1}{2}} \mathrm{~L}^{\frac{3}{2}} \mathrm{~T}^{-1}\right] \cdot \cdot \cdot \cdot \cdot \cdot
$$

\section{§. The Relation between Electricity and Magnetism.}

By equations (1) and (2), for the static system the unit of electricity, and for the dynamic system the unit of magnetism, are determined. There is now the further question, How is the unit of magnetism to be determined for the static system, and the unit of electricity for the dynamic? For this the well-known proposition of Amperre respecting the substitution for a closed galvanic current of two magnetic surfaces, which has also been adopted by Maxwell in its utmost generality and irrespective of any particular system of measurement*, is available.

For the sake of simplicity, the current-curve may be supposed plane, and the area of the plane figure inclosed by it assumed as the surface-unit. Besides the plane containing this figure, let us now imagine a parallel plane placed at an infinitesimal distance, and upon this a figure delimited congruent with the first figure and lying perpendicularly opposite to it. Now let these two plane figures be uniformly covered with equal quantities of north and south magnetism-that

* See Maxwell's 'Treatise on Electricity and Magnetism,' vol. ii. part 3, chapter iii. 
which, if we imagine ourselves going with the current round the figures, we have on the left hand with north, and the other with south magnetism. The quantity of the magnetisms is determined by the intensity of the current and the mutual distance of the planes. Let the latter be denoted by $\epsilon[\mathrm{L}]$, in which $[L]$, as always, signifies unit length, and $\epsilon$ an infinitesimal numerical value. Then, if a current-unit be assumed as the current-intensity, each of the two quantities of magnetism, apart from the sign, is to be supposed equal to a unit of magnetism divided by $\epsilon$. The pair of magnetic surfaces thus formed can replace the current in regard to all the forces exerted by it.

To express this mathematically, we have to multiply the intensity of the current by the area round which it flows, to multiply the quantity of magnetism present on one of the surfaces by the distance between the surfaces, and then to equate the two products. Now the current-intensity is a currentunit, which is a unit of electricity flowing through the cross section in unit time, and which is therefore represented by $\left[e \mathrm{~T}^{-1}\right]$; and the area round which it flows is a unit of surface, therefore $\left[\mathrm{L}^{2}\right]$. Accordingly the first product is $\left[e \mathrm{~L}^{2} \mathrm{~T}^{-1}\right]$. Further, the quantity of magnetism coming into consideration is $\frac{[m]}{\epsilon}$, and the distance between the surfaces $\epsilon[\mathrm{L}]$; so that the second product reads $\frac{[m]}{\epsilon} \epsilon[\mathrm{L}]$ or $[m L]$. We have consequently to form the following equation:-

from which results

$$
[m \mathrm{~L}]=\left[e \mathrm{~L}^{2} \mathrm{~T}^{-1}\right] \text {, }
$$

$$
\frac{[m]}{[e]}=\left[\mathrm{LT}^{-1}\right] . \quad \cdot \cdot \cdot \cdot \cdot \cdot \cdot
$$

This equation, which is only an expression of the relation established by Ampere between magnetism and electric currents, must hold good for every system of measurement; and hence we can form from it two special equations referable to the static and the dynamic systems respectively, namely:-

$$
\begin{aligned}
& \frac{\left[m_{s}\right]}{\left[e_{s}\right]}=\left[\mathrm{LT}^{-1}\right], \ldots . . . \\
& \frac{\left\lfloor m_{d}\right]}{\left[e_{d}\right]}=\left[\mathrm{LT}^{-1}\right] . .
\end{aligned}
$$

If we bring these two equations into connexion with the equations (1) and (2), for $\left[e_{s}\right]$ and $\left[m_{d}\right]$, we thereby arrive 
at the expressions for $\left[m_{s}\right]$ and $\left[e_{d}\right]$. From (1) and $(3 \mathrm{~A})$ we get by multiplication, on which $\left[e_{s}\right]$ vanishes,

$$
\left[m_{s}\right]=\left[\mathrm{M}^{\frac{1}{2}} \mathrm{~L}^{\frac{5}{3}} \mathrm{~T}^{-2}\right] ; \text {. . . . . }
$$

and from $(2)$ and $\left(3_{\mathrm{B}}\right)$ is obtained by division, $\left[m_{d}\right]$ vanishing,

$$
\left[e_{d}\right]=\left[\mathrm{M}^{\frac{1}{2}} \mathrm{~L}^{\frac{1}{2}}\right] . \quad . \quad . \quad . \quad . \quad . \quad .
$$

\section{§ 3. Maxwell's Incorrect Equations.}

Instead of the relation between electricity and magnetism deduced in the foregoing section from Ampère's proposition, and expressed in equation (3), in the equations constructed by Maxwell another relation between electricity and magnetism is implicitly expressed; for at page 240 of the second volume of his work, under (1) and (3) are found the equations

$$
[p \mathrm{C}]=\frac{\left[\mathrm{L}^{2} \mathrm{M}\right]}{\left[\mathrm{T}^{2}\right]} \text { and } \frac{[e]}{[\mathrm{C}]}=[\mathrm{T}] \text {. }
$$

Here $[e]$ signifies, as with us, the unit of electricity, and [C] represents the unit of current. By $[p]$ is understood the unit of a quantity which he calls the electrokinetic moment of a current, into the meaning of which, however, we need not here enter, since he himself, further on, puts $[p]=[m]$, and therefore we can in the first of the above equations substitute $[m]$ for $[p]$. If we then multiply the two equations together, we obtain the equation

$$
[e m]=\left[\mathrm{ML}^{2} \mathrm{~T}^{-\mathrm{I}}\right] \cdot \text {. } \cdot \text {. } \cdot \text {. }
$$

This, according to Maxwell, holds good for every system of measurement; hence in his developments it plays the same part as equation (3) does in ours.

The way in which he arrives at his equation rests upon his bringing into calculation the force exerted by a current upon a magnetic pole, in a similar manner to that in which we, in deducing equations (1) and (2), have brought in the force acting between two units of electricity, and between two units of magnetism, respectively. The force, however, which a current exerts upon a magnetic pole is electrodynamic; and from this it follows that an equation of which the deduction is based upon this force can be regarded as valid only in the dynamic system founded upon the electrodynamic forces, and not in the static system based on the electrostatic forces.

Indeed it is also manifest that Maxwell's equation (16) leads to the same result in the dynamic system of measurement as 
our equation (3), while in the static system it gives a different result. If, namely, we put, first,

$$
\left[e_{d} m_{d}\right]=\left[\mathrm{ML}^{2} \mathrm{~T}^{-1}\right]
$$

and divide this equation by (2), there comes

$$
\left[e_{d}\right]=\left[\mathrm{M}^{\frac{1}{2}} \mathrm{~L}^{\frac{1}{2}}\right] \text {, }
$$

which equation agrees with equation (5) above given. But if we put

$$
\left[e_{s} m_{s}\right]=\left[\mathrm{ML}^{2} \mathrm{~T}^{-1}\right],
$$

and divide this by (1), we get

$$
\left[m_{s}\right]=[\mathrm{M} \mathrm{L}], \cdot \cdot \cdot \cdot \cdot \cdot
$$

which is different from our equation (4), at which we arrived by employing equation (3).

By Maxwell's incorrect formula for the static magnetismunit the formulæ of other units in the static system of measures, dependent on the unit of magnetism, have been rendered also incorrect, in a not inexplicable manner.

\section{$\S 4$. The Determination of other Units.}

The units of electricity and magnetism in both systems of measures having been determined, the units for the other quantities also which occur in electric and magnetic investigations can now be easily deduced. Of these the most important only may here be mentioned.

The unit of the intensity of a current results very simply from understanding by current-intensity the quantity of electricity flowing in unit time through a cross section. Hence we only need here to divide the unit of electricity by the unit of time; and we thereby obtain, if $i$ denotes intensity, the following equations relating to the two systems :-

$$
\begin{aligned}
& {\left[i_{s}\right]=\frac{\left[e_{s}\right]}{[\mathrm{T}]}=\left[\mathrm{M}^{\frac{1}{2}} \mathrm{~L}^{\frac{s}{2}} \mathrm{~T}^{-2}\right], . . . .} \\
& {\left[i_{d}\right]=\frac{\left[e_{d}\right]}{[\mathrm{T}]}=\left[\mathrm{M}^{\frac{1}{2}} \mathrm{~L}^{\frac{1}{2}} \mathrm{~T}^{-1}\right] . . .}
\end{aligned}
$$

The unit of electromotive force is most simply determined from the condition (which holds universally) that the product from the units of electromotive force, current-intensity, and time, or (what is the same) the product from the units of electromotive force and quantity of electricity, must be equal to the unit of mechanical work. From this, namely, we obtain, 
if $\mathrm{E}$ denotes electromotive force, the equation

$$
[\mathrm{E} e]=\left[\mathrm{ML}^{2} \mathrm{~T}^{-2}\right] ; \quad \cdot \quad \cdot \quad \cdot \quad \cdot
$$

and if this equation be brought into the form

$$
[\mathrm{E}]=\frac{\left[\mathrm{ML}^{2} \mathrm{~T}^{-2}\right]}{[e]},
$$

and then applied successively to both systems, the following equations are arrived at:-

$$
\begin{aligned}
& {\left[\mathrm{E}_{s}\right]=\frac{\left[\mathrm{ML}^{2} \mathrm{~T}^{-2}\right]}{\left[e_{s}\right]}=\left[\mathrm{M}^{\frac{1}{2}} \mathrm{~L}^{\frac{1}{2}} \mathrm{~T}^{-1}\right], \ldots .} \\
& {\left[\mathrm{E}_{d}\right]=\frac{\left[\mathrm{ML}^{2} \mathrm{~T}^{-2}\right]}{\left[e_{d}\right]}=\left[\mathrm{M}^{\frac{1}{2}} \mathrm{~L}^{\frac{3}{2}} \mathrm{~T}^{-2}\right] . . .}
\end{aligned}
$$

The unit of resistance of conductors is defined as the resistance of a conductor in which the unit of electromotive force generates a current of unit intensity. We have, therefore, in order to deduce the formula for it, only to divide the unit of electromotive force by the unit of current-intensity; and then we get, if $\mathbf{R}$ denotes conductors' resistance:-

$$
\begin{aligned}
& {\left[\mathrm{R}_{s}\right]=\frac{\left[\mathrm{E}_{s}\right]}{\left[i_{s}\right]}=\left[\mathrm{L}^{-1} \mathrm{~T}\right], . . .} \\
& {\left[\mathrm{R}_{d}\right]=\frac{\left[\mathrm{E}_{d}\right]}{\left[i_{d}\right]}=\left[\mathrm{LT}^{-1}\right] .} \\
& \text {. . . . . . }
\end{aligned}
$$

Finally, the capacity of a conducting body may also be considered, by which is to be understood the quantity of electricity which the body can receive through the action of a unit of electromotive force. Since according to this definition the capacity of a body to which the unit of electromotive force can convey a unit of electricity is to be considered the unit of capacity, in order to construct the formula for the capacityunit we have to divide the electricity-unit by the unit of electromotive force; and from this we obtain, if $\mathrm{C}$ denotes capacity:-

$$
\begin{aligned}
& {\left[\mathrm{C}_{s}\right]=\frac{\left[e_{s}\right]}{\left[\mathrm{E}_{s}\right]}=[\mathrm{L}], \quad . \quad . \quad . \quad .} \\
& {\left[\mathrm{C}_{d}\right]=\frac{\left[e_{d}\right]}{\left[\mathrm{E}_{d}\right]}=\left[\mathrm{L}^{-1} \mathrm{~T}^{2}\right] . \quad . \quad . \quad .}
\end{aligned}
$$

For the sake of clearness, the units which have been successively determined in the foregoing may here be tabulated:- 
Static Measure.

$$
\begin{aligned}
& {\left[e_{s}\right]=\left[\mathrm{M}^{\frac{1}{2}} \mathrm{~L}^{\frac{3}{2}} \mathrm{~T}^{-1}\right],} \\
& {\left[m_{s}\right]=\left[\mathrm{M}^{\frac{1}{2}} \mathrm{~L}^{\frac{s}{2}} \mathrm{~T}^{-2}\right],} \\
& {\left[i_{s}\right]=\left[\mathrm{M}^{\frac{1}{2}} \mathrm{~L}^{\frac{3}{2}} \mathrm{~T}^{-2}\right],} \\
& {\left[\mathrm{E}_{s}\right]=\left[\mathrm{M}^{\frac{1}{2}} \mathrm{~L}^{\frac{3}{2}} \mathrm{~T}^{-1}\right],} \\
& {\left[\mathrm{R}_{s}\right]=\left[\mathrm{L}^{-1} \mathrm{~T}^{-1}\right],} \\
& {\left[\mathrm{C}_{s}\right]=[\mathrm{L}] .}
\end{aligned}
$$

Dynamic Measure.

$$
\begin{aligned}
& {\left[e_{d}\right]=\left[\mathrm{M}^{\frac{1}{2}} \mathrm{~L}^{\frac{2}{2}}\right],} \\
& {\left[m_{d}\right]=\left[\mathrm{M}^{\frac{1}{2}} \mathrm{~L}^{\frac{3}{2}} \mathrm{~T}^{-1}\right],} \\
& {\left[i_{d}\right]=\left[\mathrm{M}^{\frac{1}{2}} \mathrm{~L}^{\frac{1}{2}} \mathrm{~T}^{-1}\right],} \\
& {\left[\mathrm{E}_{d}\right]=\left[\mathrm{M}^{\frac{1}{2}} \mathrm{~L}^{\frac{3}{2}} \mathrm{~T}^{-2}\right],} \\
& {\left[\mathrm{R}_{d}\right]=\left[\mathrm{LT}^{-1}\right],} \\
& {\left[\mathrm{C}_{d}\right]=\left[\mathrm{L}^{-1} \mathrm{~T}^{2}\right] .}
\end{aligned}
$$

§5. Comparison of the Units of the two Systems.

In the foregoing, in determining the static units the measurement based on the electrostatic force, and in determining thedynamic units the measurement based on the electrodynamic force, were employed. The formulæ thus formed can therefore only serve to express the relation in which the units of each system stand to one another, but not to compare, as to their quantity, a unit of one of the systems with the corresponding unit of the other. For this latter purpose the ratio between the electrodynamic and the electrostatic force must also be taken into account.

In the static system the force between two quantities of electricity is expressed simply by the product of the quantities of electricity divided by the square of the distance; while the force between two quantities of magnetism has for its expression in the static system the product of the quantities of magnetism divided by the square of the distance and then multiplied by a constant factor $k$, which determines the ratio between the electrodynamic and the electrostatic force. In the case of the quantities of electricity and magnetism considered being assumed as units, the expressions of the two forces are $\left[e_{s}^{2} \mathrm{~L}^{-2}\right]$ and $k\left[m_{s}^{2} \mathrm{~L}^{-2}\right]$.

Now, in order, first, to learn more precisely the nature of the factor $k$, we will in the last expression, in accordance with $(3 \mathrm{~A})$, put for $\left[m_{s}\right]$ the product $\left[\mathrm{LT}^{-1}\right] \cdot\left[e_{s}\right]$, by which it is changed into $k\left[\mathrm{~L}^{2} \mathrm{~T}^{-2}\right] \cdot\left[e_{s}^{2} \mathrm{~L}^{-2}\right]$. Now, as in this expression the last factor $\left[e_{s}^{2} \mathrm{~L}^{-2}\right]$ represents a force (viz. the unit of force), and the whole expression is also to represent a force, the product $k\left[\mathrm{~L}^{2} \mathrm{~T}^{-2}\right]$ must be a pure numerical value, whence it follows that $k$ must be the reciprocal value of the square of a velocity. Consequently, if we choose the symbol $K$ for the latter, we can write $k=\frac{1}{\mathrm{~K}^{2}}$, by which, if at the same time we put the formula $\left[\mathrm{MLT}^{-2}\right]$, representing the force-unit, for 
$\left[e_{s}^{2} \mathrm{~L}^{-2}\right]$, we get the following expression for the force exerted by two static units of magnetism upon one another at unit distance:-

$$
\frac{\left[\mathrm{L}^{2} \mathrm{~T}^{-2}\right]}{\mathrm{K}^{2}}\left[\mathrm{MLT}^{-2}\right]
$$

The velocity denoted by $K$, which, so far as the measurements hitherto effected permit a judgment to be formed, agrees with the velocity of light in vacuo, is a quantity so important for electricity that it seems convenient to introduce a special name for it; and I propose to call it, analogously to a name introduced by Andrews into the theory of heat, the critical velocity.

Returning now to the consideration of the magnetic forces, according to the above the force exerted between two static units of magnetism at the unit of distance is equal to the fraction $\frac{\left[\mathrm{L}^{2} \mathrm{~T}^{-2}\right]}{\mathrm{K}^{2}}$ of a unit of force. The force between two dynamic units of magnetism at unit distance is, on the contrary, according to $\S 1$, equal to a unit of force. Consequently the latter force is to the former as 1 to $\frac{\left[\mathrm{L}^{2} \mathrm{~T}^{-2}\right]}{\mathrm{K}_{2}}$, or as $\mathrm{K}^{2}$ to $\left[\mathrm{L}^{2 \mathrm{~T}} \mathrm{~T}^{-2}\right]$. Since, then, the forces must at equal distances be as the products of the quantities of magnetism acting upon each other, and consequently in the present case as the square of the dynamic unit of magnetism to the square of the static unit of magnetism, these two squares must also be as $\mathrm{K}^{2}$ to $\left[\mathrm{L}^{2} \mathrm{~T}^{-2}\right]$, and the two units of magnetism themselves must therefore be as $\mathrm{K}$ to $\left[\mathrm{LT}^{-1}\right]$.

In representing this result mathematically, we must not denote the units of magnetism simply by $\left[m_{s}\right]$ and $\left[m_{d}\right]$; for these symbols represent the quantities of magnetism under consideration (taken as units) on the hypothesis that the one is measured with the aid of the electrostatic and the other with the aid of the electrodynamic force. For a comparison of the magnitudes of the two units, however, it is necessary that both be measured by the same measure-and consequently that either the dynamic unit be reduced to static measure or the static unit to dynamic measure. For these reduced values we will introduce a special symbol. To indicate that a quantity whose former symbol supposes dynamic measurement is measured according to static measure we will prefix to that symbol v. s., the initials of valor staticus; and to indicate that a quantity whose former symbol supposes static measurement is measured according to dynamic measure, we will prefix to that 
Measures for Electric and Magnetic Quantities. $\quad 391$

symbol v. d., the initials of valor dynamious. Thus, v. s. $\left[m_{d}\right]$ denotes the value measured according to static measure of the dynamic unit of magnetism, and v. d. $\left[m_{s}\right]$ the value measured according to dynamic measure of the static unit of magnetism.

With the aid of these symbols we can now express the above result as follows:-

$$
\frac{\mathrm{v} . \mathrm{s} \cdot\left[m_{d}\right]}{\left[m_{s}\right]}=\frac{\left[m_{d}\right]}{\mathrm{v} \cdot \mathrm{d} \cdot\left[m_{s}\right]}=\frac{\mathrm{K}}{\left[\mathrm{LT}^{-1}\right]} . \quad .
$$

In accordance with this, and employing the before-given formulæ for $\left[m_{s}\right]$ and $\left[m_{d}\right]$, the following two pairs of equations for the two systems of measurement can be formed:-

$$
\left[m_{s}\right]=\left[\mathrm{M}^{\frac{1}{2}} \mathrm{~L}^{\frac{5}{2}} \mathrm{~T}^{-2}\right] ; \quad \text { v. s. }\left[m_{d}\right]=\left[\mathrm{M}^{\frac{1}{2}} \mathrm{~L}^{\frac{3}{2}} \mathrm{~T}^{-1}\right] \mathrm{K} ; \text {. }
$$

v. d. $\left[m_{s}\right]=\left[\mathrm{M}^{\frac{1}{2}} \mathrm{~L}^{\frac{5}{2}} \mathrm{~T}^{-2}\right] \mathrm{K}^{-1} ; \quad\left[m_{d}\right]=\left[\mathrm{M}^{\frac{1}{2}} \mathrm{~L}^{\frac{3}{2}} \mathrm{~T}^{-1}\right]$. . (19)

From these equations corresponding equations for the units of the other quantities can also be derived.

As to the quantity $e$, we can put, in accordance with $(3 \mathrm{~A})$ and $(3 \mathrm{~B})$,

and hence also

$$
\left[e_{s}\right]=\left[m_{s}\right]\left[\mathrm{L}^{-1} \mathrm{~T}\right], \quad\left[e_{d}\right]=\left[m_{d}\right]\left[\mathrm{L}^{-1} \mathrm{~T}\right],
$$

v. d. $\left[e_{s}\right]=$ v. d. $\left[m_{s}\right]\left[\mathrm{L}^{-1} \mathrm{~T}\right]$, v.s. $\left[e_{d}\right]=$ v. s. $\left[m_{d}\right]\left[\mathrm{L}^{-1} \mathrm{~T}\right]$. By employing these values we obtain from the preceding equations:-

$$
\begin{aligned}
\frac{\text { v. s. }\left[e_{d}\right]}{\left[e_{s}\right]} & =\frac{\left[e_{d}\right]}{\text { v. d. }\left[e_{s}\right]}=\frac{\mathrm{K}}{\left[\mathrm{LT}^{-1}\right]}, . . . . . \\
{\left[e_{s}\right] } & =\left[\mathrm{M}^{\frac{1}{2}} \mathrm{~L}^{\frac{3}{3}} \mathrm{~T}^{-1}\right] ; \quad \text { v. s. }\left[e_{d}\right]=\left[\mathrm{M}^{\frac{1}{2}} \mathrm{~L}^{\frac{1}{2}}\right] \mathrm{K}, . \\
\text { v. d. }\left[e_{s}\right] & =\left[\mathrm{M}^{\frac{1}{2}} \mathrm{~L}^{\frac{3}{2}} \mathrm{~T}^{-1}\right] \mathrm{K}^{-1} ; \quad\left[e_{d}\right]=\left[\mathrm{M}^{\frac{1}{2}} \mathrm{~L}^{\frac{1}{2}}\right] .
\end{aligned}
$$

From these equations we get for $i$, conformably with (8) and $(9)$ :-

$$
\begin{aligned}
\frac{\text { v. s. }\left[i_{d}\right]}{\left[i_{s}\right]} & =\frac{\left[i_{d}\right]}{\text { v. d. }\left[i_{s}\right]}=\frac{\mathrm{K}}{\left[\mathrm{LT}^{-1}\right]}, \ldots . . . . \\
{\left[i_{s}\right] } & =\left[\mathrm{M}^{\frac{1}{2}} \mathrm{~L}^{\frac{3}{2}} \mathrm{~T}^{-2}\right] ; \quad \text { v. s. }\left[i_{d}\right]=\left[\mathrm{M}^{\frac{1}{2}} \mathrm{~L}^{\frac{1}{2}} \mathrm{~T}^{-1}\right\rceil \mathrm{K}, . \\
\text { v.d. }\left[i_{s}\right] & =\left[\mathrm{M}^{\frac{1}{2}} \mathrm{~L}^{\frac{3}{2}} \mathrm{~T}^{-2}\right] \mathrm{K}^{-1} ; \quad\left[i_{d}\right]=\left[\mathrm{M}^{\frac{1}{2}} \mathrm{~L}^{\frac{1}{2}} \mathrm{~T}^{-1}\right] .
\end{aligned}
$$

For $\mathrm{E}$ we get, from the equations for $e$ in conjunction with equations (11) and (12):-

$$
\frac{\text { v.s. }\left[\mathrm{E}_{d}\right]}{\left[\mathrm{E}_{s}\right]}=\frac{\left[\mathrm{E}_{d}\right]}{\text { v.d. }\left[\mathrm{E}_{s}\right]}=\frac{\left[\mathrm{LT}^{-1}\right]}{\mathrm{K}}, \text {. . . }
$$




$$
\left[\mathrm{E}_{s}\right]=\left[\mathrm{M}^{\frac{1}{2}} \mathrm{~L}^{\frac{1}{2}} \mathrm{~T}^{-1}\right] ; \text { v.s. }\left[\mathrm{E}_{d}\right]=\left[\mathrm{M}^{\frac{1}{1}} \mathrm{~L}^{\frac{3}{2}} \mathrm{~T}^{-2}\right] \mathrm{K}^{-1} \text {, }
$$

$$
\text { v. d. }\left[\mathrm{E}_{s}\right]=\left[\mathrm{M}^{\frac{1}{2}} \mathrm{~L}^{\frac{1}{2}} \mathrm{~T}^{-1}\right] \mathrm{K} ; \quad\left[\mathrm{E}_{d}\right]=\left[\mathrm{M}^{\frac{1}{2}} \mathrm{~L}^{\frac{3}{2}} \mathrm{~T}^{-2}\right] \text {. . }
$$

For $\mathrm{R}$ there result from the equations for $\mathrm{E}$ and $i$ in conjunction with equations (13) and (14):-

$$
\begin{aligned}
\frac{\text { v. s. }\left[\mathrm{R}_{d}\right]}{\left[\mathrm{R}^{s}\right]} & =\frac{\left[\mathrm{R}_{d}\right]}{\text { v.d. }\left[\mathrm{R}_{s}\right]}=\frac{\left[\mathrm{L}^{2} \mathrm{~T}^{-2}\right]}{\mathrm{K}^{2}}, \\
{\left[\mathrm{R}_{s}\right] } & =\left[\mathrm{L}^{-1} \mathrm{~T}\right] ; \quad \text { v.s. }\left[\mathrm{R}_{d}\right]=\left[\mathrm{LT}^{-1}\right] \mathrm{K}^{-2}, \\
\text { v. d. }\left[\mathrm{R}_{s}\right] & =\left[\mathrm{L}^{-1} \mathrm{~T}\right] \mathrm{K}^{2} ; \quad\left[\mathrm{R}_{d}\right]=\left[\mathrm{LT}^{-1}\right] . \quad .
\end{aligned}
$$

Lastly, for $\mathrm{C}$ we get from the equations for $e$ and $\mathrm{E}$ in conjunction with equations (15) and (16):-

$$
\begin{aligned}
\frac{\text { v.s. }\left[\mathrm{C}_{d}\right]}{\left[\mathrm{C}_{s}\right]} & =\frac{\left[\mathrm{C}_{d}\right]}{\text { v.d. }\left[\mathrm{C}_{d}\right]}=\frac{\mathrm{K}^{2}}{\left[\mathrm{~L}^{2} \mathrm{~T}^{-2}\right]}, . . \\
{\left[\mathrm{C}_{s}\right] } & =[\mathrm{L}] ; \quad \text { v.s. }\left[\mathrm{C}_{d}\right]=\left[\mathrm{L}^{-1} \mathrm{~T}^{2}\right] \mathrm{K}^{2}, \\
\text { v.d. }\left[\mathrm{C}_{s}\right] & =[\mathrm{L}] \mathrm{K}^{-2} ; \quad\left[\mathrm{C}_{d}\right]=\left[\mathrm{L}^{-1} \mathrm{~T}^{2}\right] .
\end{aligned}
$$

\$6. Maxwell's Statements respecting the Ratios between the Static and Dynamic Units.

On the ratios between the static and dynamic units, discussed in the foregoing section, Maxwell expresses himself differently. He gives, in his work on Electricity (vol. ii. p. 243), the following table, in which $I$ have merely taken leave to alter the letters employed for the notation so as to make them agree with our notation:-

Number of Electrostatic Units in one Electromagnetic Unit.

$$
\begin{aligned}
& \text { For } e \text { and } i \text {. . . . . . K, } \\
& " m \text { and } \mathrm{E}, \text {. . . . } \frac{1}{\overline{\mathrm{K}}} \text {, } \\
& \text { }, \mathrm{C} \cdot . \cdot . \cdot . \quad \cdot \mathrm{K}^{2} \text {, } \\
& \text { " R . . . . . . . } \frac{1}{\mathrm{~K}^{2}} \text {. }
\end{aligned}
$$

Among these statements, that which refers to the magnetism $m$ directly contradicts our equation (17), since with Maxwell $\mathrm{K}$ stands in the denominator, while in equation (17) $\mathrm{K}$ stands in the numerator. The mistake made by Maxwell in this statement is a consequence of the already mentioned oversight made by him in the construction of the expression for the electrostatic unit of magnetism. 
With respect to the rest of the statements, I think I must make one remark upon their form. I cannot admit it to be mathematically correct to say that the number of the electrostatic units in an electromagnetic (or electrodynamic) unit is equal to a velocity or to any power of a velocity. It is true that Maxwell himself has, in another passage, somewhat modified his manner of expression by adding the word " numerically" to the word "equal ;" but other authors, who have followed him in treating of the units, have paid no particular regard to this addition, but have simply retained the above form, to which they have thereby given wide diffusion.

A manner of expression of this sort permits it to be inferred that formulæ of different dimensions in respect of their quantity are compared with one another, which is inadmissible. If one wishes to compare a static unit with the corresponding dynamic unit with respect to quantity, one must, as we have above done, express both in one and the same system of measures, and consequently either reduce the dynamic unit to static measure or the static unit to dynamic measure. Thereby are obtained formulæ of equal dimensions; and when these are compared with one another, it is found, not that the number of static units is equal to a velocity or to a power of a velocity, but that it is equal to the ratio of two velocities, or equal to a power of that ratio.

I believe that in investigations like that with which we are here occupied, in which it is precisely the determination of the dimensions of the different kinds of quantities that is chiefly the question, it is essentially important that even the manner of expression in regard to the dimensions be absolutely correct.

\section{\$7. The Practical System of Measures.}

In all that has been said hitherto the question has been only, how can the units relating to electricity and magnetism be represented by the fundamental units, namely the units of mass, length, and time? The quantity which has been given to the fundamental units must now be discussed.

Gauss and Weber, who introduced the electrodynamic system of measures, selected as the units of mass, length, and time the milligram, millimetre, and second; while the British Association (who in the rest have adopted the system of Gauss and Weber) have, at the suggestion of Sir William Thomson, chosen the gram, centimetre, and second as units of mass, length, and time.

Both systems of fundamental units, however, furnish electrical units the magnitude of which is very different from the 
magnitudes to be practically measured; so that the latter can only with the aid of very large or very small numerical values be represented by those units. To avoid this inconvenience, the British Association, and in connexion with it the Congress of Electricians at Paris, have decided to multiply or divide the electrical units resulting from Thomson's system of fundamental units by certain (some of them very high) powers of 10 , and thus to form units of practically suitable magnitude.

For these latter, names borrowed from celebrated men specially meritorious with respect to this branch of physics were then chosen. Among the units we have above discussed, only one is left without a name, and, indeed, just that which forms the base of the dynamic system, namely the unit of magnetism. Hence I would take leave to propose that for it the name "weber" be introduced; for to Weber we are indebted for singularly great advances in regard to electrical measurements, and he, in conjunction with Gauss, was the founder of the electrodynamic system. Hence also, formerly, one of the units, the unit of current-intensity, was designated by his name. In the practical system now introduced, however, it turned out that the unit of current-intensity which fits into this system differs from that designated by the name of Weber in the proportion of 1 to 10 ; and as it was feared that confusion might be produced by employing the same name for the new unit, another name, ampère, was given to it. Accordingly, if the name of Weber were not introduced for the unit of another kind of quantity, it would be missing in the system of names, which would not be in keeping with justice. I therefore think I may reckon upon my proposal meeting with general assent.

The practical system of measures established by the Congress of Electricians, with the inclusion of the above-discussed unit of magnetism, if the gram and the centimetre be, as is usual, denoted by $g r$ and $\mathrm{cm}$ and the second by $s$, can be written as follows:-

$$
\begin{aligned}
& \text { Weber ...... }\left[m_{d}\right]=g r^{\frac{1}{2}} \mathrm{~cm}^{\frac{3}{2}} \mathrm{~s}^{-1} \cdot 10^{8} \text {, } \\
& \text { Coulomb ... }\left[e_{d}\right]=g r^{\frac{1}{2}} \mathrm{~cm}^{\frac{1}{2}} \cdot 10^{-1} \text {, } \\
& \text { Ampère...... }\left[i_{d}\right]=g r^{\frac{1}{2}} \mathrm{~cm}^{\frac{1}{2}} s^{-1} \cdot 10^{-1} \text {, } \\
& \text { Volt ........ }\left[\mathrm{E}_{d}\right]=g r^{\frac{1}{2}} \mathrm{~cm}^{\frac{3}{2}} \mathrm{~s}^{-2} \cdot 10^{8} \text {, } \\
& \text { Ohm ......... }\left[\mathrm{R}_{d}\right]=\mathrm{cm} \mathrm{s}^{-1} \cdot 10^{9} \text {, } \\
& \text { Farad ...... }\left[\mathrm{C}_{d}\right]=c m^{-1} s^{2} \cdot 10^{-9} \text {. }
\end{aligned}
$$


\$ 8. The Practical System of Measures as a Simple System.

In the foregoing form the practical system has the inconvenience that with every unit one must bear in mind the power of 10 by which the general formula given in $\$ 4$ is to be multiplied. Nevertheless, as the Committee of the British Association has already remarked, by a suitable selection of the fundamental units the practical can be made a simple system, in which all the units can be represented merely by the formulæ given in $\$ 4$. For this purpose $1.10^{-11} \mathrm{gr}$ must be taken as the unit of mass, and $1.10^{9} \mathrm{~cm}$ or $1.10^{7} \mathrm{~m}$ as the unit of length, while the time-unit remains 1 second.

If the length $1.10^{7} \mathrm{~m}$ be denoted by $q$ to indicate that it is equal to a quadrant of the meridian, and the mass $1.10^{-11} \mathrm{gr}$ by $p$, the practical units can be written as follows:-

$$
\begin{aligned}
& \text { Weber ........ }\left[m_{d}\right]=p^{\frac{1}{2}} q^{\frac{3}{2}} s^{-\mathrm{t}}, \\
& \text { Coulomb ..... }\left[e_{d}\right]=p^{\frac{1}{2}} q^{\frac{1}{2}}, \\
& \text { Ampère........ }\left[i_{d}\right]=p^{\frac{1}{2}} q^{\frac{1}{2}} s^{-1}, \\
& \text { Volt .......... }\left[\mathrm{E}_{d}\right]=p^{\frac{1}{2}} q^{\frac{3}{2}} s^{-2}, \\
& \text { Obm ........... }\left[\mathrm{R}_{d}\right]=q^{-1}, \\
& \text { Farad ........ }\left[\mathrm{C}_{d}\right]=q^{-1} s^{2} .
\end{aligned}
$$

This manner of representing them has manifestly the advantage of greater simplicity; and at the same time it is further to be remarked that the units of other kinds of electric and magnetic quantity, not contained in the preceding table, assume a similar simple form when these fundamental units are employed; while if $\mathrm{gr}, \mathrm{cm}, \mathrm{s}$ be used, the formula of every new unit must be provided with a specially to be determined power of 10 as a factor, by which the distinctness and ready intelligibility of the formulæ are impaired.

The circumstance that, in order to obtain at once for electric units values agreeing to some extent with the quantities we have at other times to measure, and hence convenient for us, so very small a unit of mass and so very large a unit of length must be employed, is to be regarded as a characteristic peculiarity of electricity, and hence cannot be avoided. In order, then, to facilitate the representation in investigations in which such very small and very large units occur, it is desirable to be able to state them briefly, not only by mathematical symbols, but also in words; and I would make a proposal for that purpose.

In the French system of weights and measures, as is well known, for each kind of quantity, starting from the funda- 
mental unit, the first three lower units resulting from divisions by ten are named by prefixing the words deci, centi, and milli, borrowed from the Latin, and the first four higher units, resulting from multiplications by ten, by prefixing the words deka, hekto, kilo, and myria, borrowed from the Greek. I propose, then, to employ for naming the lower units arising from further divisions by 10 , and the higher units arising from multiplications by ten, likewise Latin and Greek numerals, but ordinal numerals, which will specify the negative or positive exponents of the powers of ten by which the fundamental unit is to be multiplied; so that, for instance, with the metre the fifth lower unit $1.10^{-5} \mathrm{~m}$ will be called a quintometre, and the fifth higher unit $1.10^{5} \mathrm{~m}$ a pemptometre, and correspondently with the gram and other fundamental units*.

According to this, we have to call the mass $1.10^{-11} \mathrm{gr}$, occurring in the above systen, an undecimogram, and the length $1.10^{7} \mathrm{~m}$ a hebdometre. The practical system of measures is consequently characterized in its entirety by the name the electrodynamic system of measures undecimogram, hebdometre, second. This name easily impresses itself in the memory; and by it the aim of a more precise definition of the system is more perfectly attained than by saying that it is the electrodynamic system of measures gram, centimetre, second, in which, however, each unit must be multipied by a specially to be stated power of ten.

\section{§9. The Critical System.}

We have seen, in section 5, that, in the different kinds of electric and magnetic quantity, the ratio of the dynamic unit to the value of the static unit measured according to dynamic measure, or, what comes to the same, the ratio of the value of the dynamic unit measured according to static measure to the static unit, is always represented by a power of the ratio of the critical velocity to the velocity-unit. It thence follows that, if the fundamental units be chosen so that the velocityunit becomes equal to the critical velocity, then those ratios become each equal to 1. A system of measures in which this

* Only the higher unit resulting from multiplication by $10^{6}$ makes a little difficulty. As the sixth is "̈Kros in Greek, in accordance with the above we should have, properly, to call the quantity $1.10^{6} \mathrm{~m}$ a hectometre. But in the French system of measures the prefix hekto is already employed in another sense, namely as a contraction of éraróv, so that hektometre signifies $100 \mathrm{~m}$; and we must therefore seek help from some other source for the naming of $1.10^{6}$. To that end we might, e. $g$., deviating somewhat from Greek usage, say hexometre, or even employ the prefix mega, proposed for this order of quantity by the British Association, and form the name megametre. 
takes place will, as has been insisted by other authors, be distinguished above the rest by simplicity. Such a one may here, in conclusion, be discussed.

First, as to the time-unit to be employed in the new system, this can be selected at pleasure; but, since all the systems hitherto considered agree in having a second as the unit of time, there is no reason for choosing any other time-unit here, and we therefore retain the second.

By this determination of the time-unit the unit of length is also determined, because as such that length must be taken which a point endowed with the critical velocity would travel in one second. This amounts to approximately 30 meridianquadrants, and is consequently about 30 times the unit of length of the practical system of measures. We will denote it by $\lambda$.

There still remains to be determined the unit of mass. This has no influence upon the unit of velocity; so that any value whatever can be given to it without altering the unit of velocity; hence it appears to me most expedient so to choose this value that two of the most important electrical units, viz. those of quantity of electricity and intensity of current, take the same values in the new system of measures as in the practical system. In the latter we have, according to the preceding section, to put

$$
\left[e_{d}\right]=p^{\frac{1}{2}} q^{\frac{1}{2}} \text { and }\left[i_{d}\right]=p^{\frac{1}{3}} q^{\frac{1}{2}} s^{-1} ;
$$

and in the new system, if its unit of mass be denoted by $\mu$, the following equations must hold:-

$$
\left[e_{d}\right]=\mu^{\frac{1}{2}} \lambda^{\frac{1}{2}} ; \text { and }\left[i_{d}\right]=\mu^{\frac{1}{2}} \lambda^{\frac{1}{2}} s^{-1} .
$$

Now, if the latter values of $\left[e_{d}\right]$ and $\left[i_{d}\right]$ are to agree with the former, the products $\mu^{\frac{1}{2}} \lambda^{\frac{1}{2}}$ and $p^{\frac{1}{2}} q^{\frac{1}{2}}$ must be equal, and hence also

from which follows

$$
\begin{aligned}
& \mu \lambda=p q, \text {. . . . . . } \\
& \mu=p \frac{q}{\lambda} \text {. . . . . . . . }
\end{aligned}
$$

Hereby the determination of $\mu$ is reduced to the determination of $\lambda$, and consequently to the determination of the critical velocity; and from what has been said above respecting the approximate value of $\lambda$, it results that $\mu$ is approximately $\frac{1}{30}$ undecimogram or $\frac{1}{3}$ duodecimogram - that is, a three billionth of a gram.

Phil. Mag. S. 5. Vol, 13. No. 83. June 1882. 
This system, in which the velocity-unit is equal to the critical velocity, may be called the critical system of measures; and here the values corresponding to it of the electric and magnetic units may also be collected:-

$$
\begin{aligned}
& {\left[m_{d}\right]=\text { v.d. }\left[m_{s}\right]=\mu^{\frac{1}{2}} \lambda^{\frac{5}{2}} s^{-1}=\frac{\lambda}{q} \text { weber, }} \\
& {\left[e_{d}\right]=\text { v. d. }\left[e_{s}\right]=\mu^{\frac{1}{2}} \lambda^{\frac{1}{2}}=1 \text { coulomb, }} \\
& {\left[i_{d}\right]=\text { v.d. }\left[i i_{s}\right]=\mu^{\frac{1}{2}} \lambda^{\frac{3}{3}} s^{-1}=1 \text { ampère, }} \\
& {\left[\mathrm{E}_{d}\right]=\text { v. d. }\left[\mathrm{E}_{s}\right]=\mu^{\frac{1}{2}} \lambda^{\frac{3}{2}} s^{-2}=\frac{\lambda}{q} \text { volt, }} \\
& {\left[\mathrm{R}_{d}\right]=\text { v.d. }\left[\mathrm{R}_{s}\right]=\lambda s^{-1}=\frac{\lambda}{q} \text { ohm, }} \\
& {\left[\mathrm{C}_{d}\right]=\text { v.d. }\left[\mathrm{C}_{s}\right]=\lambda^{-1} s^{2}=\frac{q}{\lambda} \text { farad. }}
\end{aligned}
$$

Although this critical system of measures is not suited for practical measurements, and especially for the preparation of standards, because the critical velocity is not yet known with sufficient precision, yet it may offer great conveniences in theoretic investigations, on account of the accordance between the values of the static and dynamic units.

L. On the Question of Electrification by Evaporation. By S. H. Freeman, Fellow in Physics, Johns Hopkins University, Baltimore, Md.*

T $\mathrm{T}$ has been very commonly believed that evaporation is an 1 important source of atmospheric electricity. So far as this belief has an experimental basis, it is to be found in the researches of Pouillet $\dagger$ and of Tait and Wanklyn $\neq$. In comparison with their work the experiments of Volta, Saussure, and others are of little value. As the result of an elaborate series of experiments, Pouillet came to the following conclusions:-

1. Simple changes of state never give the least sign of electrification.

* Communicated by the Author.

† Annales de Chimie et de Physique, sér. 2, tome xxxr. p. 401, and xxxvi. p. 4.

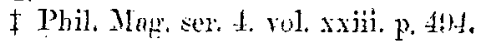

